\title{
Studies on Corrosion of Annealed and Aged 18 Ni 250 Grade Maraging Steel in Sulphuric Acid Medium
}

\author{
T. Poornima, ${ }^{1}$ Nayak Jagannatha, ${ }^{2}$ A. Nityananda Shetty ${ }^{3, *}$ \\ ${ }^{1}$ Department of Science and Humanities, PESIT Bangalore-560085, India \\ ${ }^{2}$ Department of Metallurgy and Materials Engineering, National Institute of Technology, \\ Karnataka, Surathkal, Srinivasnagar - 575 025, Karnataka, India \\ $3^{3 *}$ Department of Chemistry, National Institute of Technology, Karnataka, Surathkal, \\ Srinivasnagar-575 025, Karnataka, India.
}

Received 26 August 2009; accepted 15 April 2010

\begin{abstract}
The corrosion behavior of aged and annealed sample of $18 \mathrm{Ni} 250$ grade maraging steel was investigated in varied conditions of concentration and temperature of sulphuric acid medium, using electrochemical techniques like Tafel polarization and electrochemical impedance spectroscopy (EIS). The results obtained from both the techniques are in good agreement. These results have shown increase in corrosion rate of aged specimen with increase in concentration and temperature of sulphuric acid. With increase in concentration of sulphuric acid from $0.025 \mathrm{M}$ to $0.25 \mathrm{M}$ the corrosion rate of annealed sample was found to increase, but there after in $0.5 \mathrm{M}, 0.75 \mathrm{M}$ and $1 \mathrm{M}$, the rate of corrosion decreases, indicating passivation of alloy surface at higher concentration of sulphuric acid. The corrosion rate of aged specimen was found to be higher than that of the annealed specimen. Similar observations are revealed by SEM images. The thermodynamic parameters like activation energy, enthalpy of activation and entropy of activation were calculated.
\end{abstract}

Keywords: maraging steel, acidic solutions, EIS, polarization, SEM, hydrogen overpotential.

\section{Introduction}

Corrosion of structural elements is a major issue for any industry because of the chemical environment of the chemical processing. Maraging steels are a special class of ultra high strength steels that differ from conventional ones in that they are hardened by a metallurgical reaction that does not involve carbon. Instead,

\footnotetext{
* Corresponding author. E-mail address: nityashreya@gmail.com
} 
these steels are strengthened by the precipitation of intermettalic compounds at temperatures of about $480{ }^{\circ} \mathrm{C}$. Maraging steels have slightly better corrosion resistance than tempered martensite alloy steels. In industrial and marine atmospheres, the corrosion rates of maraging steel are about half of those of conventional steels. In saline and acidic solutions, maraging steels show somewhat better corrosion resistance. They derive high strength from age hardening of low carbon, Fe-Ni martensitic matrix [1-2]. The characteristics of this grey and white steel are high ductility, formability, corrosion resistance, high temperature strength and easy to fabricate, weld and treat with heat, and maintain an invariable size even after heat treatment [3]. These steels have emerged as alternative materials to conventional quenched and tempered steels for advanced technologies such as aerospace, nuclear and gas turbine applications. They frequently come in contact with acids during cleaning, pickling, descaling, acidizing, etc. Sulphuric acid is one of the most aggressive acids for iron and its alloys, and is often used as a picking acid for steel and its alloys. But very less study appears to be done in the area of corrosion behavior and corrosion inhibition of maraging steel. So it is intended to study the corrosion behavior of maraging steel in sulphuric acid medium.

According to available literature, atmospheric exposure of $18 \mathrm{Ni}$ maraging steel leads to corrosion in a uniform manner and it becomes completely rust covered [4]. Pit depths tend to be shallower than high strength steels [5]. Bellanger et al. [6] have shown the effect of slightly acid $\mathrm{pH}$ with or without chloride ion in radioactive water on the corrosion of maraging steel, and reported that corrosion behavior of maraging steel at the corrosion potential depends on $\mathrm{pH}$ and intermediates remaining on maraging steel surface in the active region favoring the passivity. The effect of carbonate ions in slightly alkaline medium on the corrosion of maraging steel was investigated by Bellanger, which reveals that corrosion potential does not change with carbonate ions at a constant $\mathrm{pH}$ [7]. Heat treatment affects the corrosion rate. Critical and passive current densities increase as the structure is varied from fully annealed to fully aged [8]. Maraging steels are found to be less susceptible to hydrogen embrittlement than common high strength steels owing to significantly low diffusion of hydrogen in them [9]. Several technical papers covering alloy design, material processing, thermo-mechanical treatments, welding, strengthening mechanisms, etc., have been published [10]. The stress corrosion cracking behavior and also hydrogen embrittlement in these steels have been studied quite extensively. The present paper reports the results of studies carried out on the corrosion of $18 \mathrm{Ni} 250$ grade maraging steel in sulphuric acid medium.

\section{Experimental \\ Material}

The maraging steel samples (M 250 grade) in annealed and aged condition were taken from plates which were subjected to solution annealing treatment at $1088 \pm$ $5 \mathrm{~K}$ for 1 hour followed by air cooling. Percentage composition of $18 \mathrm{Ni} 250$ grade maraging steel samples in annealed and aged condition is given in Table 1. 
Cylindrical test coupons were cut from the plate and sealed with epoxy resin in such a way that the area exposed to the medium is $0.503 \mathrm{~cm}^{2}$. These coupons were polished as per standard metallographic practice, subjected to belt grinding, followed by polishing on emery papers, finally on polishing wheel using legated alumina to obtain mirror finish, degreased with acetone, washed with distilled water and dried before immersing in the medium.

Table 1. Composition of the specimen.

\begin{tabular}{cccc}
\hline Element & Composition $^{[1]}$ & Element & Composition $^{[1]}$ \\
\hline $\mathrm{C}$ & $0.015 \%$ & $\mathrm{Ti}$ & $0.3-0.6 \%$ \\
$\mathrm{Ni}$ & $17-19 \%$ & $\mathrm{Al}$ & $0.005-0.15 \%$ \\
$\mathrm{Mo}$ & $4.6-5.2 \%$ & $\mathrm{Mn}$ & $0.1 \%$ \\
$\mathrm{Co}$ & $7-8.5 \%$ & $\mathrm{P}$ & $0.01 \%$ \\
$\mathrm{Si}$ & $0.1 \%$ & $\mathrm{~S}$ & $0.01 \%$ \\
$\mathrm{O}$ & $30 \mathrm{ppm}$ & $\mathrm{N}$ & $30 \mathrm{ppm}$ \\
$\mathrm{H}$ & $2.0 \mathrm{ppm}$ & $\mathrm{Fe}$ & Balance \\
\hline$[1] \%$ by weight & & &
\end{tabular}

\section{Medium}

Standard solutions of sulphuric acid having concentrations $0.025 \mathrm{M}, 0.05 \mathrm{M}$, $0.25 \mathrm{M}, 0.5 \mathrm{M}, 0.75 \mathrm{M}$ and $1 \mathrm{M}$, were prepared by diluting analar grade sulphuric acid by using double distilled water. Experiments were carried out using calibrated thermostat at temperatures $303 \mathrm{~K}, 308 \mathrm{~K}, 313 \mathrm{~K}, 318 \mathrm{~K}, 323 \mathrm{~K}( \pm 0.5$ $\mathrm{K})$, and solution was not deaerated during the electrochemical testing.

\section{Electrochemical measurements}

Electrochemical measurements were carried out in a potenciostat/galvanostat AUTOLAB model PGSTAT30 controlled by a PC through the general purpose electrochemical system (GPES) and frequency response analyzer (FRA) software provided by AUTOLAB. EIS and Tafel polarization measurements were carried out using a conventional three electrode Pyrex glass cell with platinum counter electrode and saturated calomel electrode (SCE) as reference electrode. All the values of potential are therefore referred to the SCE. Finely polished annealed and aged maraging steel specimens of $0.503 \mathrm{~cm}^{2}$ surface area were exposed to corrosion medium of sulphuric acid having the above mentioned concentrations at different temperatures.

The potentiodynamic current-potential curves were recorded by polarizing the specimen to $-250 \mathrm{mV}$ cathodically and $+250 \mathrm{mV}$ anodically with respect to OCP at the scan rate of $5 \mathrm{mV} / \mathrm{s}$. Electrochemical impedance spectroscopy (EIS), which gives early information about the electrochemical processes at the metal solution interface, has been used in many reports on corrosion studies [11-12]. The corrosion behavior of the specimen in annealed and aged condition was also investigated by EIS technique. In EIS technique a small amplitude of an AC signal of $10 \mathrm{mV}$ and frequency from $100 \mathrm{kHz}$ to $0.01 \mathrm{~Hz}$ were recorded and impedance data were analyzed. The charge transfer resistance $R_{t}$ was obtained from Nyquist plot. The value of $\mathrm{R}_{\mathrm{t}}$ is inversely proportional to the corrosion rate 
[13] and the $R_{p}$ values obtained from Tafel polarization are compared with $R_{t}$ values obtained from Nyquist's plot for good agreement.

In all the above measurements, at least three similar results were considered and their average values are reported.

The scanning electron microscope images were recorded to establish the interaction of acid medium with the metal surface using JEOL JSM-6380LA analytical scanning electron.

\section{Results and discussions}

\section{Tafel polarization measurements}

The corrosion behaviors of annealed and aged samples of maraging steel specimens were investigated at the above mentioned concentrations of sulphuric acid at different temperatures using Tafel polarization technique. The potentiodynamic polarization parameters, including corrosion potential $\left(\mathrm{E}_{\text {corr }}\right)$, corrosion current $\left(\mathrm{I}_{\text {corr }}\right)$, polarization resistance $\left(\mathrm{R}_{\mathrm{p}}\right)$, anodic and cathodic slopes $\left(b_{a}\right.$ and $\left.b_{c}\right)$, and corrosion rate, obtained from the Tafel studies, are summarised in Tables 2 and 3 for annealed and aged samples, respectively. Fig. 1 and 2 represent potentiodynamic polarization curves of annealed and aged maraging steel specimens in sulphuric acid as a function of concentration of sulphuric acid at $303 \mathrm{~K}$.

\section{Effect of temperature}

Temperature is an important parameter in studies on material corrosion. The dependence of temperature on corrosion rate reveals valuable thermodynamic parameters like energy of activation, enthalpy and entropy of activation for the corrosion process. The corrosion rate in acid solutions increases exponentially with increase in temperature, because the hydrogen evolution overpotential decreases with increase in temperature [14]. The corrosion of steel normally proceeds via two partial reactions in acid solutions. The partial anodic reaction involves the oxidation of metal and formation of soluble $\mathrm{Fe}^{2+}$ ions, while the partial cathodic reaction involves the evolution of hydrogen gas. It is clear from the data presented in Tables 1 and 2 that the corrosion rate of both annealed and aged specimens increases with increasing in the temperature of sulphuric acid medium from $303 \mathrm{~K}$ to $323 \mathrm{~K}$. This may be attributed to the fact that the hydrogen evolution overpotential decreases with increase in temperature that leads to increase in cathodic reaction rate [15]. These results are in agreement with the observation reported by Jones that, in open system, the corrosion rate of iron increases with temperature up to $353 \mathrm{~K}$ [16]. For annealed samples, with increase in temperature, corrosion potential $\left(\mathrm{E}_{\text {corr }}\right)$ and anodic Tafel slope $\left(\mathrm{b}_{\mathrm{a}}\right)$ values were not affected significantly; but a significant change in values of cathodic Tafel slope $\left(b_{c}\right)$ was observed. This may be due to the change in hydrogen overvoltage, which in turn affects the cathodic polarization curve. This may be also due to the contribution from concentration polarization [17], which leads to deviation of cathodic curve from Tafel behavior at lower cathodic potentials, since the variation in $b_{c}$ is more prominent at lower concentrations of 
acid. In aged specimen Tafel slopes remain approximately the same. This indicates that increase in temperature does not change the mechanism of corrosion reaction. The variation of corrosion rate with temperature was utilized to calculate the thermodynamic parameters such as activation energy $\left(E_{a}\right)$, enthalpy of activation $(\Delta \mathrm{H})$ and entropy of activation $(\Delta \mathrm{S})$.

Table 2. Results of Tafel polarization and the electrochemical impedance studies for the annealed specimen.

\begin{tabular}{|c|c|c|c|c|c|c|c|c|}
\hline \multirow{2}{*}{$\begin{array}{l}\text { Molarity } \\
\mathrm{H}_{2} \mathrm{SO}_{4}\end{array}$} & \multicolumn{7}{|c|}{ Tafel polarization results } & \multirow{2}{*}{$\begin{array}{c}\begin{array}{c}\text { EIS } \\
\text { results }\end{array} \\
\begin{array}{c}\mathbf{R}_{\mathrm{ct}} \\
\left(\mathrm{ohm} \mathrm{cm}^{2}\right)\end{array}\end{array}$} \\
\hline & $\begin{array}{c}\mathbf{T} \\
(\mathbf{K})\end{array}$ & $\begin{array}{c}\mathbf{E}_{\text {corr }} \\
(\mathrm{V} / \mathrm{SCE})\end{array}$ & $\underset{\left(\mathrm{ohm} \mathbf{~ c m}^{2}\right)}{\mathbf{R}_{\mathrm{p}}}$ & $\begin{array}{c}i_{\text {corr }} \\
\left(\times 10^{-4} \mathrm{~A} / \mathrm{cm}^{2}\right)\end{array}$ & $\begin{array}{c}\mathbf{b}_{\mathrm{c}} \\
(\mathrm{V} / \mathrm{dec})\end{array}$ & $\begin{array}{c}\mathbf{b}_{\mathbf{a}} \\
(\mathrm{V} / \mathrm{dec})\end{array}$ & $\begin{array}{l}\text { Corrosion rate } \\
\quad(\mathbf{m m} / \mathbf{y})\end{array}$ & \\
\hline \multirow[t]{5}{*}{0.025} & 303 & -0.387 & 45.7 & 3.3 & 0.130 & 0.080 & 3.9 & 47.7 \\
\hline & 308 & -0.388 & 42.7 & 3.9 & 0.139 & 0.089 & 4.6 & 38.1 \\
\hline & 313 & -0.389 & 41.4 & 4.3 & 0.149 & 0.096 & 5.1 & 31.2 \\
\hline & 318 & -0.389 & 36.1 & 5.5 & 0.149 & 0.113 & 6.4 & 23.5 \\
\hline & 323 & -0.392 & 29.5 & 6.4 & 0.150 & 0.129 & 7.4 & 16.9 \\
\hline \multirow[t]{5}{*}{0.05} & 303 & -0.384 & 29.2 & 5.4 & 0.145 & 0.087 & 6.3 & 23.4 \\
\hline & 308 & -0.382 & 24.2 & 8.6 & 0.168 & 0.113 & 9.8 & 18.2 \\
\hline & 313 & -0.387 & 21.5 & 10.7 & 0.176 & 0.110 & 12.5 & 13.6 \\
\hline & 318 & -0.386 & 19.7 & 12.4 & 0.145 & 0.119 & 14.3 & 9.9 \\
\hline & 323 & -0.387 & 17.8 & 15.2 & 0.152 & 0.123 & 16.6 & 8.8 \\
\hline \multirow[t]{5}{*}{0.25} & 303 & -0.352 & 11.5 & 10.2 & 0.114 & 0.079 & 11.8 & 13.0 \\
\hline & 308 & -0.351 & 8.5 & 16.8 & 0.112 & 0.087 & 17.3 & 11.8 \\
\hline & 313 & -0.351 & 7.0 & 19.2 & 0.101 & 0.078 & 22.3 & 8.9 \\
\hline & 318 & -0.351 & 6.1 & 24.5 & 0.110 & 0.091 & 28.5 & 6.4 \\
\hline & 323 & -0.349 & 5.1 & 27.7 & 0.117 & 0.094 & 32.1 & 5.2 \\
\hline \multirow[t]{5}{*}{0.5} & 303 & -0.324 & 15.0 & 6.5 & 0.119 & 0.038 & 7.0 & 14.8 \\
\hline & 308 & -0.326 & 12.8 & 9.7 & 0.121 & 0.041 & 11.3 & 12.1 \\
\hline & 313 & -0.325 & 10.2 & 14.5 & 0.100 & 0.043 & 15.5 & 9.4 \\
\hline & 318 & -0.326 & 8.3 & 13.7 & 0.128 & 0.050 & 19.3 & 7.6 \\
\hline & 323 & -0.323 & 7.1 & 11.4 & 0.116 & 0.052 & 22.9 & 6.2 \\
\hline \multirow[t]{5}{*}{0.75} & 303 & -0.304 & 28.2 & 2.1 & 0.115 & 0.036 & 2.5 & 1.2 \\
\hline & 308 & -0.303 & 16.9 & 2.7 & 0.100 & 0.030 & 3.6 & 20.3 \\
\hline & 313 & -0.301 & 13.2 & 4.5 & 0.102 & 0.035 & 5.2 & 12.9 \\
\hline & 318 & -0.307 & 11.9 & 6.0 & 0.107 & 0.034 & 7.5 & 11.2 \\
\hline & 323 & -0.306 & 8.7 & 8.7 & 0.09 & 0.34 & 9.4 & 8.2 \\
\hline \multirow[t]{5}{*}{1.0} & 303 & -0.298 & 39.2 & 1.5 & 0.110 & 0.039 & 1.8 & 41.2 \\
\hline & 308 & -0.300 & 29.8 & 2.8 & 0.107 & 0.033 & 3.1 & 30.4 \\
\hline & 313 & -0.299 & 22.6 & 5.1 & 0.107 & 0.035 & 5.0 & 23.9 \\
\hline & 318 & -0.298 & 18.5 & 5.8 & 0.104 & 0.034 & 6.5 & 18.7 \\
\hline & 323 & -0.301 & 14.7 & 6.5 & 0.110 & 0.038 & 7.3 & 15.2 \\
\hline
\end{tabular}


Table 3. Results of Tafel polarization and the electrochemical impedance studies for the aged specimen.

\begin{tabular}{|c|c|c|c|c|c|c|c|c|}
\hline \multirow{2}{*}{$\begin{array}{c}\text { Molarity } \\
\mathrm{H}_{2} \mathrm{SO}_{4}\end{array}$} & \multicolumn{7}{|c|}{ Tafel polarization results } & \multirow{2}{*}{$\begin{array}{c}\begin{array}{c}\text { EIS } \\
\text { results }\end{array} \\
\begin{array}{c}\mathbf{R}_{\mathrm{ct}} \\
\left(\mathrm{ohm} \mathrm{cm}^{2}\right)\end{array}\end{array}$} \\
\hline & $\begin{array}{c}\mathbf{T} \\
(\mathbf{K})\end{array}$ & $\begin{array}{c}\mathbf{E}_{\text {corr }} \\
(\mathrm{V} / \mathrm{SCE})\end{array}$ & $\underset{\left(\mathrm{ohm} \mathrm{cm}^{2}\right)}{\mathbf{R}_{\mathrm{p}}}$ & $\left(\begin{array}{c}\mathbf{i}_{\text {corr }} \\
\mathbf{A} \\
\mathrm{A} / \mathrm{cm}^{2}\end{array}\right)$ & $\begin{array}{c}\mathbf{b}_{\mathbf{c}} \\
(\mathrm{V} / \mathbf{d e c})\end{array}$ & $\begin{array}{c}\mathbf{b}_{\mathbf{a}} \\
(\mathrm{V} / \mathrm{dec})\end{array}$ & $\begin{array}{l}\text { Corrosion rate } \\
\qquad(\mathrm{mm} / \mathrm{y})\end{array}$ & \\
\hline \multirow[t]{5}{*}{0.025} & 303 & -0.393 & 39.3 & 4.2 & 0.089 & 0.075 & 5.5 & 40.3 \\
\hline & 308 & -0.393 & 36.5 & 5.5 & 0.066 & 0.063 & 6.9 & 37.7 \\
\hline & 313 & -0.401 & 32.3 & 6.8 & 0.096 & 0.077 & 8.0 & 34.5 \\
\hline & 318 & -0.395 & 28.8 & 7.6 & 0.088 & 0.087 & 9.2 & 30.2 \\
\hline & 323 & -0.405 & 25.6 & 8.7 & 0.108 & 0.097 & 9.9 & 27.7 \\
\hline \multirow[t]{5}{*}{0.05} & 303 & -0.373 & 19.3 & 8.9 & 0.121 & 0.104 & 10.4 & 20.9 \\
\hline & 308 & -0.370 & 18.7 & 10.5 & 0.132 & 0.107 & 12.3 & 18.2 \\
\hline & 313 & -0.370 & 16.9 & 12.9 & 0.134 & 0.150 & 15.4 & 16.1 \\
\hline & 318 & -0.373 & 16.5 & 14.6 & 0.138 & 0.137 & 17.8 & 15.4 \\
\hline & 323 & -0.374 & 14.0 & 17.5 & 0.168 & 0.167 & 20.4 & 12.7 \\
\hline \multirow[t]{5}{*}{0.25} & 303 & -0.337 & 5.7 & 36.3 & 0.094 & 0.091 & 40.5 & 5.3 \\
\hline & 308 & -0.329 & 5.1 & 48.9 & 0.121 & 0.132 & 55.3 & 4.4 \\
\hline & 313 & -0.334 & 4.0 & 56.5 & 0.123 & 0.132 & 64.5 & 3.8 \\
\hline & 318 & -0.328 & 3.5 & 64.9 & 0.119 & 0.123 & 70.0 & 3.4 \\
\hline & 323 & -0.327 & 3.2 & 72.6 & 0.126 & 0.130 & 82.2 & 3.0 \\
\hline \multirow[t]{5}{*}{0.5} & 303 & -0.310 & 3.4 & 75.2 & 0.107 & 0.103 & 87.3 & 2.8 \\
\hline & 308 & -0.312 & 4.8 & 83.9 & 0.122 & 0.127 & 99.1 & 2.3 \\
\hline & 313 & -0.309 & 1.9 & 96.5 & 0.112 & 0.112 & 112 & 1.6 \\
\hline & 318 & -0.312 & 1.8 & 107.5 & 0.118 & 0.118 & 124 & 1.4 \\
\hline & 323 & -0.311 & 1.5 & 117.2 & 0.110 & 0.110 & 136 & 1.3 \\
\hline \multirow[t]{5}{*}{0.75} & 303 & -0.303 & 2.6 & 81.2 & 0.083 & 0.088 & 94.3 & 3.1 \\
\hline & 308 & -0.303 & 2.1 & 93.9 & 0.116 & 0.099 & 109 & 2.7 \\
\hline & 313 & -0.302 & 1.8 & 103.7 & 0.100 & 0.115 & 120 & 2.4 \\
\hline & 318 & -0.299 & 1.6 & 116.8 & 0.132 & 0.125 & 135 & 2.2 \\
\hline & 323 & -0.298 & 1.5 & 130 & 0.120 & 0.116 & 147 & 1.8 \\
\hline \multirow[t]{5}{*}{1.0} & 303 & -0.283 & 1.8 & 99.8 & 0.129 & 0.098 & 110.3 & 2.6 \\
\hline & 308 & -0.286 & 1.5 & 108.7 & 0.136 & 0.122 & 123.2 & 2.3 \\
\hline & 313 & -0.284 & 1.3 & 126 & 0.148 & 0.115 & 146.1 & 1.9 \\
\hline & 318 & -0.285 & 1.2 & 142 & 0.138 & 0.134 & 153.6 & 1.5 \\
\hline & 323 & -0.284 & 1.0 & 165 & 0.155 & 0.112 & 174.8 & 1.2 \\
\hline
\end{tabular}




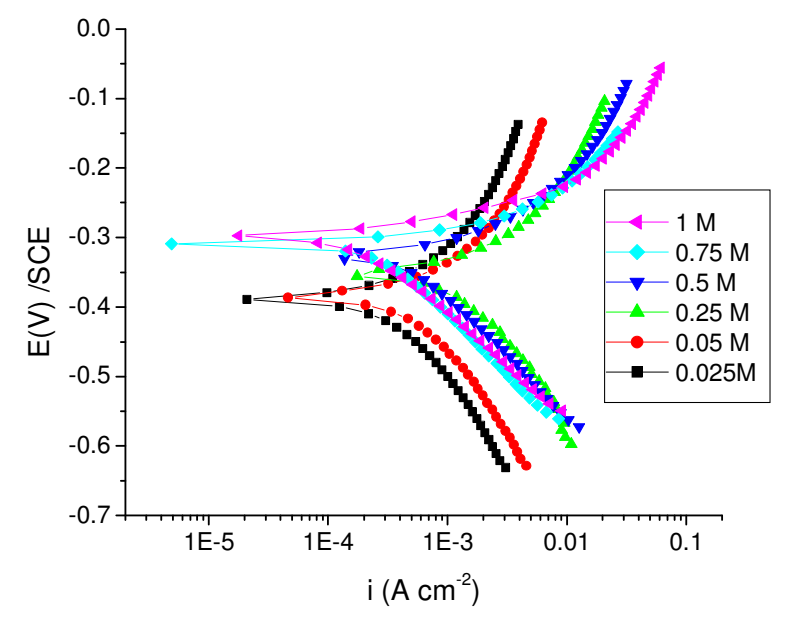

Figure 1. Polarisation curves of annealed maraging steel specimens in different concentrations of sulphuric acid at $303 \mathrm{~K}$.

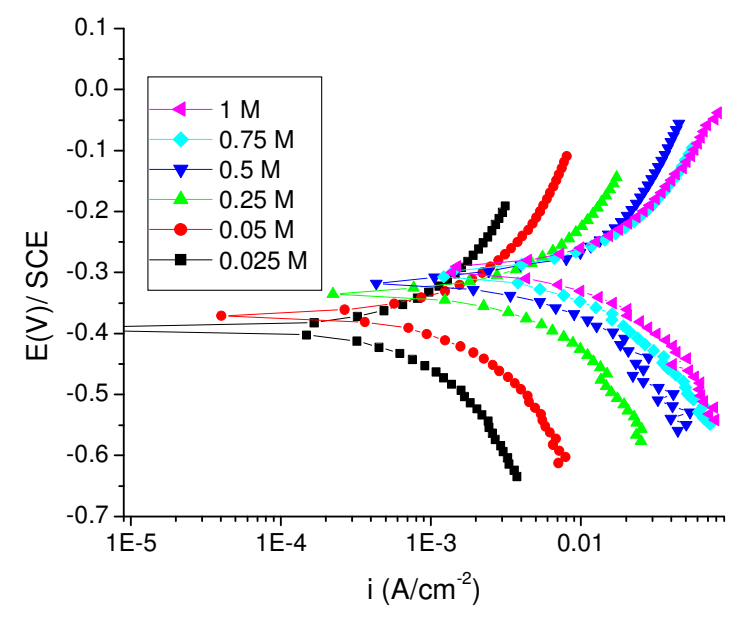

Figure 2. Polarisation curves of aged maraging steel specimens in different concentrations of sulphuric acid at $303 \mathrm{~K}$.

According to Arrhenius law equation [18],

$$
\ln \mathrm{k}=\mathrm{A}-\left(\mathrm{E}_{\mathrm{a}} / \mathrm{RT}\right)
$$

where $\mathrm{k}$ is the rate constant, $\mathrm{A}$ is Arrhenius constant which depends on the metal type, $\mathrm{E}_{\mathrm{a}}$ is the activation energy of the corrosion process, $\mathrm{R}$ is the universal gas constant and $\mathrm{T}$ is the absolute temperature. The plot of $\ln$ (corrosion rate) vs. reciprocal of absolute temperature, $1 / \mathrm{T}$, gives straight line whose slope $=-\mathrm{Ea} / \mathrm{R}$, from which the value of activation energy is calculated. The Arrhenius plots for the annealed and aged specimens are shown in Fig. 3 and Fig. 4, respectively. Thus calculated values of activation energy are given in Table 4. Entropy and enthalpy of activation $(\Delta \mathrm{H}$ and $\Delta \mathrm{S})$ were calculated from transition state theory (equation 2) [19]: 


$$
\mathrm{k}=(\mathrm{RT} / \mathrm{Nh}) \exp (\Delta \mathrm{S} / \mathrm{R}) \exp (-\Delta \mathrm{H} / \mathrm{RT})
$$

where $\mathrm{h}$ is Plank's constant, $\mathrm{N}$ is Avogadro's number. A plot of $\ln$ (corrosion rate $/ \mathrm{T})$ vs. $1 / \mathrm{T}$ gives straight line with slope $=-\Delta H / R$ and intercept $=\ln (\mathrm{R} / \mathrm{Nh})$ $+\Delta \mathrm{S} / \mathrm{R}$ (Fig. 5 and Fig. 6). The significance of these parameters is explained under the effect of concentration.

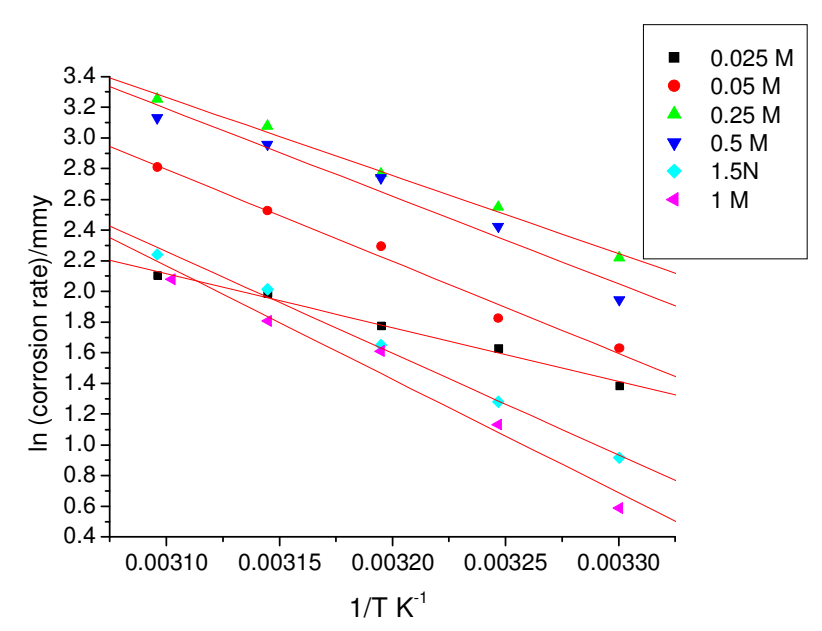

Figure 3. Arrhenius plots for annealed specimen of maraging steel in sulphuric acid.

\section{Effect of concentration}

As can be seen from Fig. 1 and Fig. 2 the corrosion potential is shifted in the positive direction, when the concentration of sulphuric acid is increased. The positive shift in the corrosion potential, $\mathrm{E}_{\mathrm{corr}}$, with increase in concentration of acid indicates that the anodic process is much more affected than the cathodic process [20]. This observation is in accordance with Murralidharan et al. [21], who proposed dependence of $\mathrm{E}_{\text {corr }}$ and $\mathrm{I}_{\text {corr }}$ on solution parameters. It is evident from Fig. 1 and Table 2 that in case of aged specimen the corrosion rate increases with increase in concentration of sulphuric acid, and maximum corrosion is observed in $1 \mathrm{M}$ sulphuric acid. Whereas in case of annealed specimen, as seen from Fig. 2 and Table 3, the corrosion rate increases with increase in concentration of sulphuric acid from $0.025 \mathrm{M}$ to $0.25 \mathrm{M}$. But on further increase in concentration of sulphuric acid from $0.5 \mathrm{M}$ to $1 \mathrm{M}$, the corrosion rate decreases. This may be due to the passivation of the alloy surface at high concentrations of sulphuric acid. The shift in $\mathrm{E}_{\text {corr }}$ towards noble values may be an indication of passivation. As can be observed in Fig. 2, for annealed specimen, with the increase in anodic potential, the corrosion current density initially increases exponentially and then becomes gradual. Passivity refers to loss of chemical reactivity experienced by certain metals and alloys under particular environmental conditions. The metals most susceptible to this kind of behavior are iron, nickel, silicon, chromium, titanium and alloys containing these metals [22]. Although literature is not available in terms of passivity of maraging steel in sulphuric acid, many reports are available regarding the passivation of iron and its alloys in sulphuric acid. According to a number of authors, anodic passivity of 
metals results from the formation of oxide and hydroxide films in the reaction of metals with water. In general, the formation of passive film may occur according to solid state reaction mechanism [23-25].

$$
\mathrm{nM}+\mathrm{mH}_{2} \mathrm{O} \rightarrow \mathrm{M}_{\mathrm{n}} \mathrm{O}_{\mathrm{m}}+2 \mathrm{mH}^{+}+2 \mathrm{me}^{-}
$$

or precipitation reaction,

$$
\mathrm{M}^{2+}+\mathrm{nH}_{2} \mathrm{O} \rightarrow \mathrm{M}(\mathrm{OH})_{2}(\mathrm{n}-2) \mathrm{H}_{2} \mathrm{O}+2 \mathrm{H}^{+}
$$

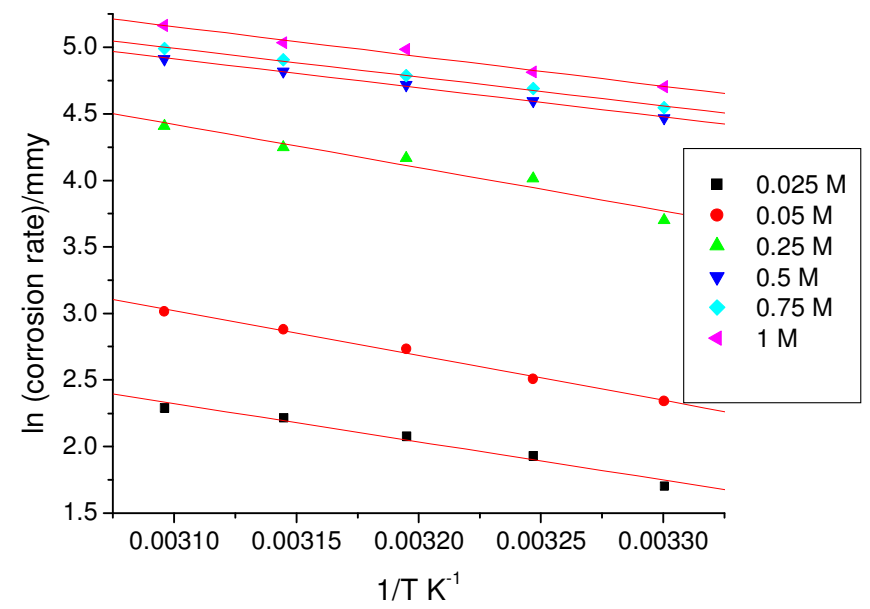

Figure 4. Arrhenius plots for aged specimen of maraging steel in sulphuric acid.

Table 4. Activation parameters of corrosion reaction of annealed and aged specimens in sulphuric acid.

\begin{tabular}{ccccccc}
\hline Molarity & \multicolumn{2}{c}{$\mathbf{E}_{\mathbf{a}}(\mathbf{k J} / \mathbf{m o l})$} & \multicolumn{2}{c}{$\Delta \mathbf{H}(\mathbf{k J} / \mathbf{m o l})$} & \multicolumn{2}{c}{$\Delta \mathbf{S}(\mathbf{J} / \mathbf{m o l} / \mathbf{K})$} \\
\cline { 2 - 7 } $\mathbf{H}_{\mathbf{2}} \mathbf{S O}_{\mathbf{4}}$ & Annealed & Aged & Annealed & Aged & Annealed & Aged \\
\hline 0.025 & 29.19 & 26.87 & 23.59 & 21.45 & -156 & -160 \\
0.05 & 37.86 & 27.97 & 35.26 & 25.37 & -113 & -141 \\
0.25 & 40.83 & 26.97 & 38.23 & 25.31 & -98 & -131 \\
0.5 & 47.46 & 18.09 & 44.86 & 15.4 & -80 & -156 \\
0.75 & 55.11 & 17.95 & 52.51 & 15.35 & -64 & -157 \\
1.0 & 57.88 & 18.59 & 55.28 & 15.99 & -57 & -153 \\
\hline
\end{tabular}

According to Boguscaw et al., passivation of iron in sulphuric acid (1 M) solution is a result of metal water reaction, which is evidenced by thin hydrated oxyhydroxide layer as detected by XPS [26]. El-Kot et al. reported the formation of passivating film on iron electrode upon anodic oxidation in sulphuric acid and also dependence of passivation on the concentration of the acid [27]. 


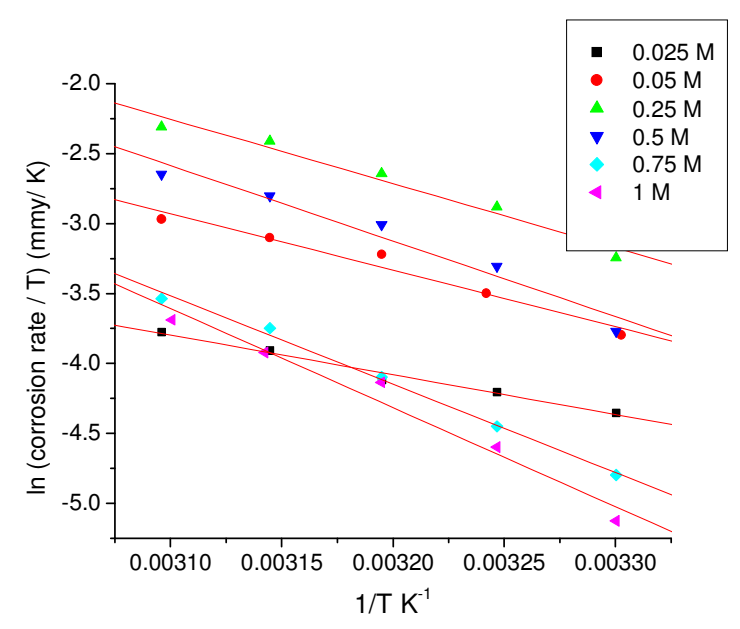

Figure 5. $\ln ($ corrosion rate/T) vs. $1 / \mathrm{T}$ plot for annealed sample of maraging steel in sulphuric acid.

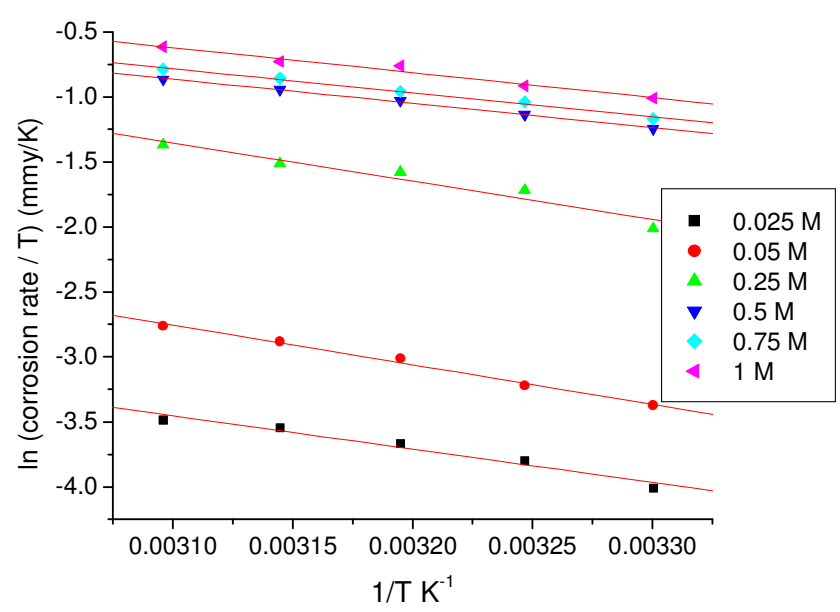

Figure 6. Polarisation curve of annealed maraging steel specimen in $1 \mathrm{M}$ sulphuric acid solution at $303 \mathrm{~K}$.

For annealed specimen, the anodic and cathodic Tafel slopes $\left(b_{a}\right.$ and $\left.b_{c}\right)$ showed approximately a constant value at lower concentration of sulphuric acid $(0.025$ $\mathrm{M}, 0.05 \mathrm{M}$ and $0.25 \mathrm{M}$ ), indicating that the corrosion mechanism remains the same in lower concentrations of acid [20]. At higher concentrations of acid (0.5 $\mathrm{M}, 0.75 \mathrm{M}$ and $1 \mathrm{M}$ ) also, $b_{\mathrm{a}}$ and $\mathrm{b}_{\mathrm{c}}$ values remained constant, but the values are different from those obtained at lower concentrations. This indicates that the mechanism of corrosion process is different at lower concentration levels and higher concentration levels; and mechanism remaining the same within the concentration ranges mentioned at both the levels. The values of cathodic Tafel slopes at higher concentration $\left(b_{c}, 120 \mathrm{mV} / \mathrm{dec}\right)$ suggest that the hydrogen evolution reaction (HER) is independent of sulphate ion concentration, the rate 
determining step in the HER is the discharge reaction, a result which agrees with previous works [17,28-29].

$$
\mathrm{H}^{+}+\mathrm{e}^{-} \rightarrow \mathrm{H}
$$

On the other hand, lower $b_{a}$ values are in accordance with Bockris mechanism [29] of dissolution/deposition of iron, reproduced below.

$$
\begin{gathered}
\mathrm{Fe}+\mathrm{H}_{2} \mathrm{O} \leftrightarrows \mathrm{FeOH}+\mathrm{H}^{+}+\mathrm{e}^{-} \\
\mathrm{FeOH} \rightarrow \mathrm{FeOH}^{+}+\mathrm{e}^{-} \\
\mathrm{FeOH}^{+}+\mathrm{H}^{+} \leftrightarrows \mathrm{Fe}^{2+}+\mathrm{H}_{2} \mathrm{O}
\end{gathered}
$$

The activation parameters for the corrosion process are listed in Table 4. These values indicate that the energy of activation for corrosion process is higher for annealed samples than for aged samples, in confirmation with the difference in their corrosion rates, as discussed in the earlier section. A very high value of activation energy obtained for annealed specimen at higher concentration of acid may be an evidence for passivation of alloy surface at higher concentrations of sulphuric acid. The entropy of activation for the corrosion process, calculated from transition state theory equation, is found to be highly negative in both the cases of annealed and aged samples. This implies that the activated complex in the rate determining step represents association rather than dissociation, indicating that a decrease in disorder takes place, on going from reactant to the activated complex [19].

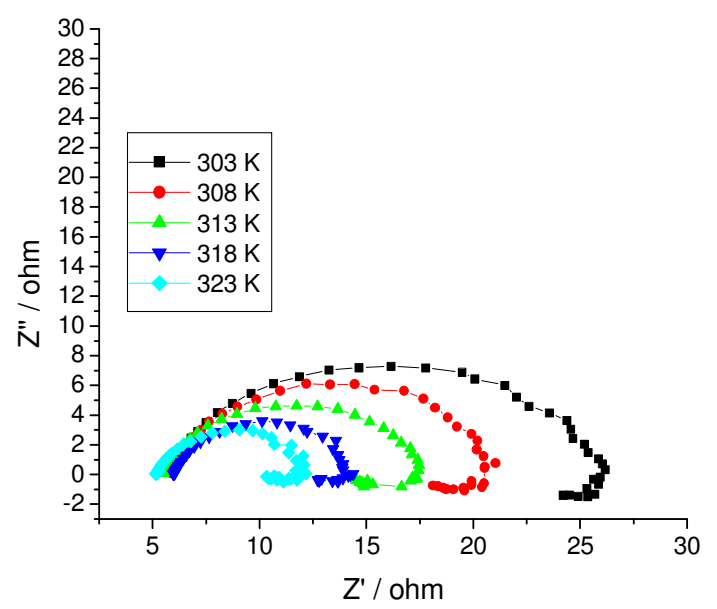

Figure 7. Nyquist diagrams of annealed maraging steel at different temperatures in $0.25 \mathrm{M}$ sulphuric acid.

From the results of Tafel polarization we can observe that the corrosion rate of annealed specimen is less when compared with aged specimen in sulphuric acid medium. This may be attributed due to the fact that annealed specimens are 
solution treated and air cooled. Annealed specimens contain entirely martensitic matrix which is composed of predominantly iron and nickel. Hence, corrosion behavior of annealed samples is similar to that of iron and nickel in acid medium. Aging results in precipitation of intermetallics. Since these intermetallics have different composition, their electrochemical behavior is expected to be different compared to matrix [30]. Also, there will be strain fields around these coherent precipitates as a result of lattice mismatch between the precipitate and the matrix, due to the difference in the crystal structure and lattice parameters. These strain fields in combination with the galvanic effect due to the composition difference leads to the enhanced corrosion of aged samples than the annealed samples.

\section{Electrochemical impedance spectroscopy}

The results of potentiodynamic polarization experiments were confirmed by impedance measurements, since EIS is a powerful technique in studying corrosion mechanism. In order to get more information about the corrosion behavior of annealed and aged maraging steel specimens, EIS measurements were carried out in sulphuric acid medium at different concentrations and temperatures and they are displayed as Nyquist plots in the present study. The Nyquist plots obtained for annealed samples of maraging steel specimens in various acid concentrations and temperatures are as shown in Fig. 7 and Fig. 8, respectively. The present study shows depressed capacitive loop at high frequency range (HF) followed by an inductive loop that is observed in low frequency (LF) region. The impedance spectra for different Nyquist plots were analysed by fitting the experimental data to the equivalent circuit model, as given in Fig. 9, which has been used previously to model iron/acid interface [13]. The constant phase element is introduced in the circuit instead of pure double layer capacitor to give more accurate fit [31].

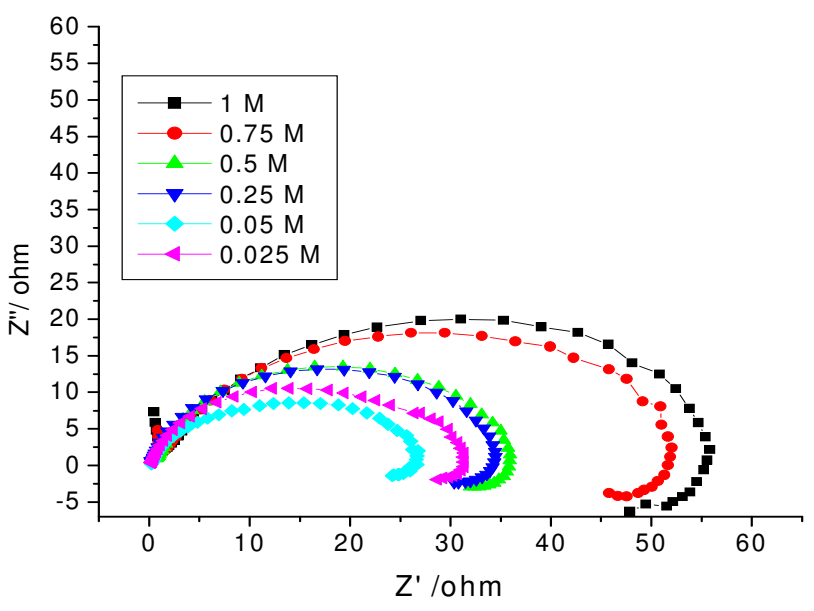

Figure 8. Nyquist diagrams of annealed maraging steel in different concentrations of sulphuric acid at $303 \mathrm{~K}$. 
The HF capacitive loop $\mathrm{R}_{\mathrm{ct}}-\mathrm{CPE}$ can be attributed to charge transfer reaction. These are not perfect semicircles, because the Nyquist plots obtained in the real system represent a general behavior where the double layer at the metal solution interface does not behave as an ideal capacitor [32-33]. The LF inductive loop $\mathrm{R}_{\mathrm{L}}-\mathrm{L}$ can be attributed to relaxation process obtained by adsorbed sulphate ions and protons [34-35]. The point of intersection between inductive loop and the real axis represents $\left(R_{s}+R_{c t}\right)$. $R_{s}$ represents solution resistance due to the ohmic resistances of corrosion product films and the solution enclosed between the working electrode and the reference electrode. $\mathrm{R}_{\mathrm{ct}}$ represents the charge transfer resistance whose value is a measure of electron transfer across the surface and is inversely proportional to corrosion rate [36]. The corrosion current density $\mathrm{I}_{\text {corr }}$ can be calculated using charge transfer resistance $R_{c t}$, together with Stern-Geary equation 4 [20].

$$
\mathrm{I}_{\text {corr }}=\frac{\mathrm{b}_{\mathrm{a}} \mathrm{b}_{\mathrm{c}}}{2.303 \mathrm{Rc}_{\mathrm{t}} \mathrm{A}\left(\mathrm{b}_{\mathrm{a}}+\mathrm{b}_{\mathrm{c}}\right)}
$$

where $\mathrm{A}$ is the area of cross section of material under observation.

The value of $\mathrm{R}_{\mathrm{ct}}$ is inversely proportional to corrosion rate. Hence, EIS results agree with the results obtained from Tafel polarization. The $R_{c t}$ values obtained from Nyquist plot are in good agreement with $R_{p}$ values obtained from Tafel polarization.

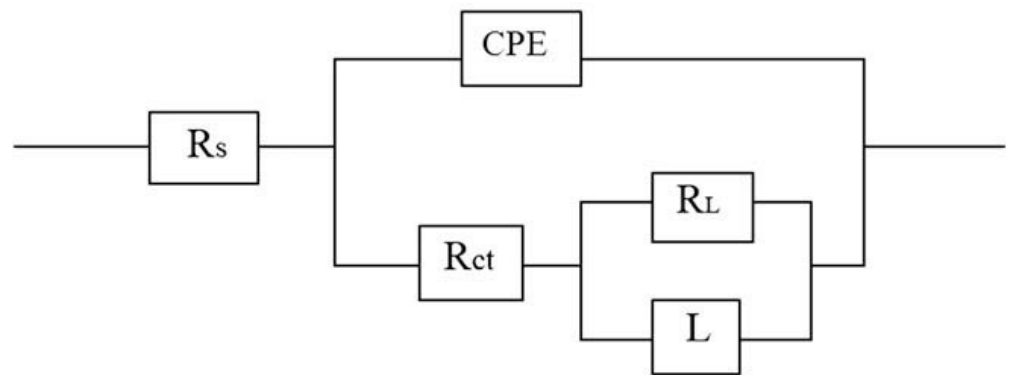

Figure 9. Equivalent circuit used to fit experimental EIS data for the corrosion of maraging steel specimen in sulphuric acid.

\section{Scanning electron microscope studies (SEM)}

The SEM images of freshly polished surface of annealed and aged specimens of maraging steel are given in Fig. 10(a) and Fig. 11(a) which show uncorroded surface with few scratches due to polishing. The surface morphology of the annealed and aged samples was examined by SEM immediately after corrosion tests in sulphuric acid medium. The SEM images of corroded annealed samples in Fig. 10(b) show degradation of the alloy. In the case of aged samples this degradation is highly pronounced, as shown in Fig. 11(b). In both type of alloys the attack by sulphuric acid is more at grain boundary since these regions are highly susceptible to corrosion. In aged samples the intermetallic precipitation at grain boundary may be responsible for higher rate of corrosion when compared to annealed samples. 


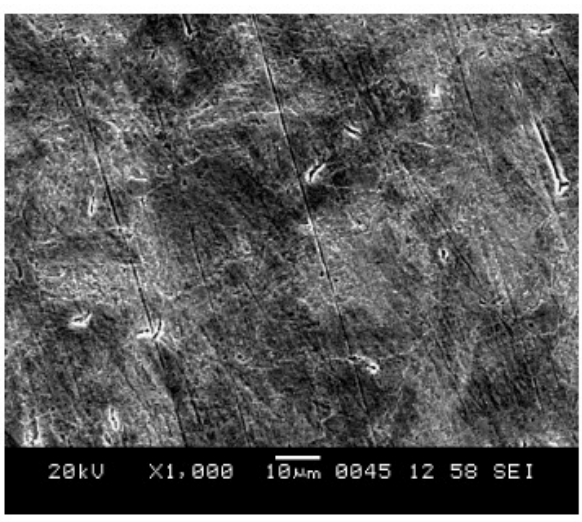

10(a)

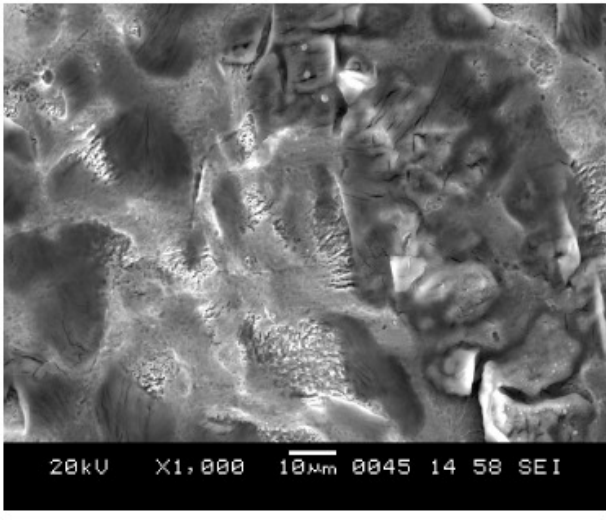

10(b)

Figure 10. SEM images of annealed maraging steel specimen. (a. Freshly polished surface. b. After immersion in sulphuric acid).

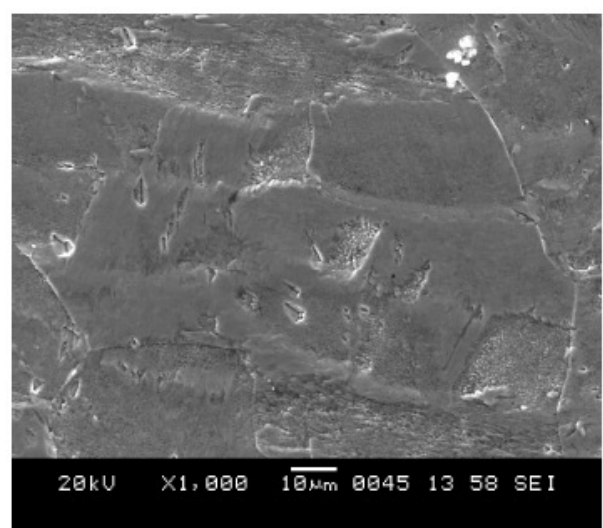

11(a)

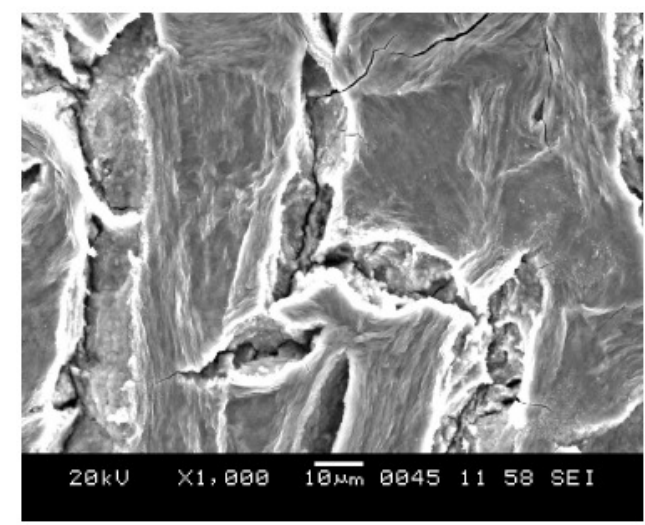

11(b)

Figure 11. SEM images of aged maraging steel specimen. (a. Freshly polished surface. b. After immersion in sulphuric acid).

\section{Conclusions}

Based on the results of this investigation, the following conclusions may be drawn.

1. The corrosion rate of both annealed and aged specimens is influenced by temperature and concentration of sulphuric acid medium.

2. The corrosion rate of aged specimens under investigation increases with increase in concentration and temperature of sulphuric acid medium.

3. The corrosion rate of annealed specimen increases with increase in concentration of sulphuric acid medium up to $0.25 \mathrm{M}$, but at $0.5 \mathrm{M}$ and above, passivation of alloy surface may be responsible for decrease in corrosion rate. With increase in temperature corrosion rate increases.

4. The corrosion kinetics follows Arrhenius law.

5. The corrosion rate of aged sample is higher when compared with the annealed specimen in sulphuric acid medium due to galvanic effect and strain fields. 


\section{References}

1. K.Y .Sastry, R. Narayanan, C.R Shamantha, S.S Sunderason, S.K. Seshadri, V.M. Radhakrishnan, K.J.L. Iyer and S. Sundararajan, Mater. Sci. Technol. 19 (2003) 375. [10.1179/026708303225010632]

2. ASM Handbook, vol.1,10 ${ }^{\text {th }}$ ed, $1990,796$.

3. D.G. Lee, K.C. Jang, J.M. Kuk, I.S. Kim, Journal of Materials Processing Technology 162 (2005) 342. [10.1016/j.jmatprotec.2005.02.102]

4. W.W. Krick, R.A. Covert, T.P. May, Met. Eng. Quart. 8 (1968) 31.

5. S.W. Dean, H.R. Copson, Corrosion 21 (1965) 95.

6. G. Bellanger, J.J. Rameau, J. Nucl. Mater. 228 (1996) 24. [10.1016/00223115(95)00218-9]

7. G. Bellanger, J. Nucl. Mat. 217 (1994) 187. [10.1016/0022-3115(94)90319-0]

8. Data bulletin on $18 \% \mathrm{Ni}$ maraging steel, The International Nickel Company, INC, 1964.

9. J. Rezek, I.E. Klein, J. Yhalom, Corros. Sci. 39 (1997) 385. [10.1016/S0010938X(97)83353-7]

10. P.P. Sinha, IIM Metal News 2 (1999) 5.

11. P. Bommersbach, C. Alemany-Dumont, J.-P. Millet, B. Normand, Electrochim. Acta 51 (2005) 1076. [10.1016/j.electacta.2005.06.001]

12. W.A. Badawy, K.M. Ismail, A.M. Fathi, Electrochim. Acta 51 (2006) 4186.

13. E. Poorqasemi, O. Abootalebi, M. Peikari, F. Haqdar, Corros. Sci. 51 (2009) 1043. [10.1016/j.corsci.2009.03.001]

14. A. Popova, E. Sokolova, S. Raicheva, M. Christov, Corr. Sci. 45 (2003) 33. [10.1016/S0010-938X(02)00072-0]

15. L. Larabi, Y. Harek, O. Benali, S. Ghalem, Prog. Org. Coat. 54 (2005) 256. [10.1016/j.porgcoat.2005.06.015]

16. F.N. Speller, Corrosion causes and prevention, $3^{\text {rd }}$ edition, McGraw Hill, 1951,168 .

17. E.J. Kelly, J. Electrochem. Soc. 112 (1965) 124. [10.1149/1.2423480]

18. M. Bouklah, B. Hammouti, A. Aounti, T. Benhadda, Prog. Org. Coat. 49 (2004) 225. [10.1016/j.porgcoat.2003.09.014]

19. S.S. Abd Ei-Rehim, M.A.M. Ibrahim, K.F. Khaled, J. Appl. Electrochem. 29 (1999) 593. [10.1023/A:1003450818083]

20. A. El- Sayed, J. Appl. Electrochem. 27 (1997) 193. [10.1023/A:1018456008267]

21. V.S. Muralidharan, K.S. Rajagopalan, Corros. Sci. 19 (1979) 207. [10.1016/0010-938X(79)90018-0]

22. M.G. Fontana, Corrosion Engineering, $3^{\text {rd }}$ ed., McGraw-Hill Book Co. $1987,470$.

23. W.J. Lorenz, A.A. El Milgy, D. Geana, Electrochim. Acta 20 (1975) 273. [10.1016/0013-4686(75)90005-5]

24. P. Lorbeer and W.J. Lorenz, Corros. Sci, 20 (1980) 405. [10.1016/0010938X(80)90008-6] 
25. P. Lorbear, W.J. Lorenz, Electrochim. Acta 25 (1980) 375. [10.1016/00134686(80)87026-5]

26. B. Mazurkiewicz, Electrochim. Acta 38 (1993) 502. [10.1016/00134686(93)85004-I]

27. A.M. El-Kot, S. Abd El Haleem, S. Mohammed, Monatsheftefur Chemie 123 (1992) 965. [10.1007/BF00810926]

28. J.O. M. Bockris, D. Drazic, Electrochim. Acta 7 (1962) 293. [10.1016/00134686(62)87007-8]

29. M.A. Devanathan, Z. Stachurski, J. Electrochem. Soc. 111 (1964) 619. [10.1149/1.2426195]

30. D.W. Shoesmith, Metals Handbook, $9^{\text {th }}$ edition, vol. $13,18$.

31. B.A. Boukamamp, Solid State Ionics 20 (1980) 31. [10.1016/01672738(86)90031-7]

32. Sha Cheng, Shougang Chen, Tao Liu, Xueting Chang, Yansheng Yin, Electrochim. Acta 52 (2007) 5936.

33. M. Ozcan, I. Dehri, M. Erbil, Appl. Surf. Sci. 236 (2004) 159. [10.1016/j.apsusc.2004.04.017]

34. M.A. Amin, S.S. Abd El-Rehim, E.E.F. El-Sherbini, R.S. Bayyomi, Electrochim. Acta 52 ( 2007) 3588. [10.1016/j.electacta.2006.10.019]

35. M.A. Veloz, I. Gonzalez, Electrochim. Acta 48 (2002) 135. [10.1016/S00134686(02)00549-2]

36. H.H. Hassan, E. Abdelghani, M.A. Amin, Electrochim. Acta 52 (2007) 6359. [10.1016/j.electacta.2007.04.046] 